\title{
Analysis of long-term functional results of radical mastoidectomy
}

\author{
HORIA MOCANU ${ }^{1 *}$, ADELA-IOANA MOCANU ${ }^{2}$, ALEXANDRU BONCIU $^{3}$, \\ GABRIELLA COADÄ $\breve{4}^{4}$, MIHAI-ADRIAN SCHIPOR ${ }^{5}$ and MARIAN RĂDULESCU ${ }^{6 *}$ \\ ${ }^{1}$ Department of ENT \& HNS, Faculty of Medicine, 'Titu Maiorescu' University, 031593 Bucharest; \\ ${ }^{2}$ Department of ENT \& HNS, Polimed Medical Center, 040067 Bucharest; ${ }^{3}$ Department of ENT \& HNS, \\ 'Dr. Carol Davila' Central Military Emergency University Hospital, 010825 Bucharest; \\ ${ }^{4}$ Department of ENT \& HNS, 'Sf. Maria' Clinical Hospital, 011172 Bucharest, Romania; \\ ${ }^{5}$ Technical University of Munich, Institute of Astronomical and Physical Geodesy, D-80333 Munich, Germany; \\ ${ }^{6}$ Department of ENT \& HNS, 'Carol Davila' University of Medicine and Pharmacy, 020021 Bucharest, Romania
}

Received June 11, 2021; Accepted July 13, 2021

DOI: $10.3892 / \mathrm{etm} .2021 .10650$

\begin{abstract}
We performed a long-term, retrospective, non-controlled study on the functional results of mastoidectomy (both radical and modified radical) and defined the relevant statistical factors that may influence the hearing outcome. In a cohort of 200 patients, we performed both radical and modified radical mastoidectomy (MRM) and followed them clinically for a period of 8.12 years. The functional results were defined by the analytical function of the severity and the period of evolution of the disease. These parameters were defined by assessing the pre-operative absolute hearing threshold (AHT), bone conduction threshold (BCT) and age of the patient at the moment of the operation. The two parameters evolved inversely proportional to the functional results and represented a complete and precise analytical tool. The global average hearing gain ratio was $32 \%$ and the ratio for unmodified pre-operative hearing (status quo ante) was $61 \%$. With favorable prognostic factors, the average gain rate was $56 \%$ and the hearing-loss rate was 5\% (1-dB SPL nominal value). The maximum ratio for gain was $81 \%$ and for hearing loss this was $0 \%$.
\end{abstract}

\section{Introduction}

In the 16th century, Ambroise Paré was the first to perform a mastoidectomy, for the same clinical reasons it is performed today (1). Unfortunately, medical services at the time were

Correspondence to: Dr Adela-Ioana Mocanu, Department of ENT \& HNS, Polimed Medical Center, 280 Calea Văcărești, 040067 Bucharest, Romania

E-mail: adela.ioana.mocanu@gmail.com

*Contributed equally

Key words: middle ear, mastoidectomy, otitis media, attic, cholesteatoma, functional results, quality of life rudimentary and rather palliative, and were provided mainly in monastic hospitals, especially for poor people and the anatomic (drainage results) suffered greatly from lack of sanitary conditions (2). Functional results of the surgery were still a future concern, and the patient was considered fortunate to survive the suppurative mastoiditis and only lose the sense of hearing to the affected ear. In the 19th century, Küster \& Bergmann (1891) were equally credited with describing the first radical mastoidectomy and from there the surgical technique began its development $(3,4)$.

The generic term mastoidectomy describes a procedure that addresses the inflammatory status of the middle ear. A successful mastoidectomy is expected to deliver a 'dry, safe, stable ear, free of disease'. Maintaining or improving hearing is important but the pursuit of a hearing result should not compromise this primary aim (5). Restoring sound transmission to the inner ear through reconstruction of the ossicular chain is paramount in middle ear surgery $(6,7)$ but useless without a well performed mastoidectomy. This type of surgery is notorious for bringing the patient into the operating room only after the ear discharge has been going on 'long enough' to cause concern. It is certain that no one questions the drainage role of the procedure (cavity cleanliness), but the common belief is that the functional results are poor (hearing is destroyed or at least gravely impaired). Mastoidectomy could be considered as anathema since this procedure requires the patients hearing in exchange for a dry, safe ear or even to save the patient's life. But is this conviction founded?

Hearing loss represents one of the most serious afflictions confronting the world's population, with variable etiology, of which at least $50 \%$ cases are genetic. However, WHO estimates that between 65 and 330 million individuals suffer from some form of middle ear suppuration and $50 \%$ of them suffer from hearing impairment (8-10).

\section{Patients and methods}

We initiated the retrospective non-controlled study by conducting a random selection of 200 long-term patients with both radical canal-wall down (CWD) and modified 
radical mastoidectomy (MRM), performed over a 3-year period. The techniques for both types of surgery are well known and described in the literature (11-13). The initial cohort was comprised of 209 patients of which 9 died ( 8 of causes non-related to middle-ear disease, 1 directly related to middle-ear disease after otogenic brain abscess). The basic statistical criteria for the selection was post-operative time span. Data analysis began in 2004 giving a post-operative follow-up period of 8.12 years for the entire cohort, from the moment of surgery and 7.86 years from the time of complete epithelization of the cavity, which allowed us to consider it as long-term evaluation. All patients were clinically evaluated (microscope otoscopy), both before surgery and after surgery. A pre-operative measurement of the absolute thresholds of hearing (AHT) and bone conduction threshold (BCT) (between $0.5-2 \mathrm{kHz}$ ) was performed and used as a statistical indicator for functional results of the mastoidectomy. Audiometric control took place as follows: 2 months post-operative (corresponding to the moment of complete epithelization of the cavity for $80 \%$ of cases); 1-year post-operative (complete epithelization of the cavity for all cases); 2 years post-operative; 3-4 years post-operative and another 2 times over the next 3 years (starting from the 5th up to the 8th year).

Our main goal was to define the situations and factors that influenced hearing results of mastoidectomy and to provide us with various aspects of the functional prognosis. Based on the selection criteria of the studied group and by performing statistical analysis of the correlation of functional results and statistically significant variables, we were able to formulate pertinent conclusions regarding the functional success rate of mastoidectomy.

Although largely clinical, our study also included minimal statistical analysis including creating Microsoft Excel databases and attributing codes to facilitate data analysis using Excel and SPSS version 15.00 (IBM Corp.). Factors such as age of the patient, presence of cholesteatoma, and stage of disease were correlated with the functional results of the mastoidectomy. Data are expressed as percentage, mean values and standard deviation. The level of statistical significance was set as $\mathrm{P} \leq 0.05$. Parametric tests (Student's t-test) or non-parametric tests (Mann-Whitney) were also applied.

\section{The studied variables}

Pre-surgery variables. The pre-surgery variables included: age group: $0-10$ years $(n=1), 11-20$ years $(n=4), 21-30$ years $(n=56), 31-40$ years $(n=45), 41-50$ years $(n=49), 51-60$ years $(n=27), 61-70$ years $(n=15), 71-80$ years $(n=3)$; and clinical stage of the disease: complicated $(n=45)$, not complicated $(n=155)$. The type of disease included: cholesteatoma $(n=56)$ and non-cholesteatoma $(n=144)$, and the type of tympanic membrane perforation included marginal $(n=75)$ and central $(n=125)$.

Intraoperative data. The intraoperative data included type of mastoidectomy: modified radical $(n=125)$, radical $(n=75)$, and ossicular chain status: absent $(n=13)$, complete and mobile $(n=27)$, complete and fixed $(n=25)$, interrupted $(n=135)$. Total lesional score was: 0-19 $(n=170), 20-39$ $(n=13), 40-59(n=5), 60-79(n=5), 80-99(n=4), 100-119$ $(n=2), 140-159(n=1)$.
Follow-up data. The follow-up data included the period for complete epithelization of the cavity: 2 months, 1 year, 2 years, 3-4 years, 8 years; and cavity self-cleansing: present or absent; as well as the mastoidectomy result (drainage effect): Failure or success.

The proportion of severe and profound hearing loss [71-100 dB SPL (decibel sound pressure level)] was 17\%, and the total hearing loss (>120 dB SPL) was $11 \%$ (Fig. 1). The distribution of mild (31-50 dB SPL) (39\%) and moderate hearing loss (51-70 dB SPL) (33\%) were also noted. One could speculate that these values were under the direct actions of the normal probability law. For pre-operative bone conduction threshold (BCT), those up to $30 \mathrm{~dB}$ represent $60 \%$ of the cases while those between $31-40 \mathrm{~dB}$ included $18 \%$. The first group corresponds to pure conduction type hypoacusis while the second is shared by conduction and mixed hypoacusis. For groups above $41 \mathrm{~dB}$, we consider them as part of mixed or sensorineural hypoacusis (Fig. 1). For well-defined pre-operative clinical situations, we considered that 0-30 dB represents a sufficient cochlear reserve for favorable functional prognosis of the surgery. Above $31 \mathrm{~dB}$, the cochlear reserve is considered insufficient for functional gain.

Fig. 2 shows how the two thresholds interacted within the studied cohort and confirm that the difference between them was situated within a well-defined interval (only low BCT allowed for 50-60 dB difference, with an average of $35 \mathrm{~dB}$ ). High thresholds allow an under-average difference but only up to $10-15 \mathrm{~dB}$.

We defined age at the time of surgery as: physical time, duration of evolution, aging (progressive degradation of function at different rates), an unstoppable increase in damaged cell proportion, increase of degree or intensity of disease, rise of hearing thresholds; all of these being included in a formalized model (physical-mathematical model). The influence of patient's age on AHT and BCT are depicted in Figs. 3 and 4. The distribution of absolute pre-operative hearing thresholds in relation to the state of the ossicular chain (OC) are presented in Fig. 5 and signify the analytical influence the physical and functional state of the $\mathrm{OC}$ has on hearing results but cannot entirely explain the intimate mechanisms of normal or pathological sound transmission. It is surprising that age (duration of disease evolution) offers an obvious causal connection as an analytical function to the AHT while the state of the OC offers an equally obvious connection but of a statistical type. In other words, for age, the connection is direct as simple, cause $\rightarrow$ effect while for OC status the connection is indirect, as cause $\rightarrow$ unknown parameters $\rightarrow$ effect, even more so since the basis of our discussion is the transmission of sound waves through the ossicular chain.

Fig. 6 shows the distribution of relative frequencies of AHT in relation to the type of disease and states the negative influence of cholesteatoma. This statistical information contradicts the common belief that cholesteatoma tends to preserve hearing for longer periods compared to non-cholesteatoma middle-ear inflammatory disease.

The influence of the type of perforation on hearing thresholds proved inconsistent and inconsequential (Fig. 7). This indicates that the type of perforation is wrongly considered as having diagnostic and prognostic value at least from a functional standpoint if not from a physical one. 


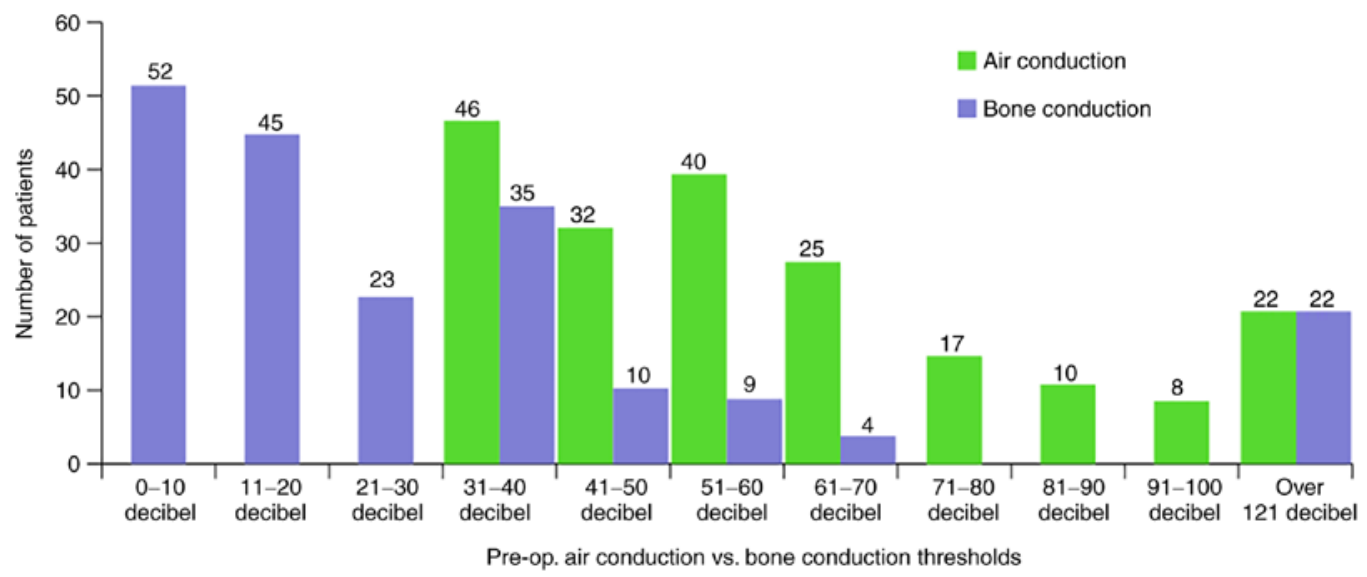

Figure 1. Pre-operative absolute threshold of hearing (AHT) vs. threshold of bone conduction (BCT) for frequencies of $0.5-2 \mathrm{kHz}$.

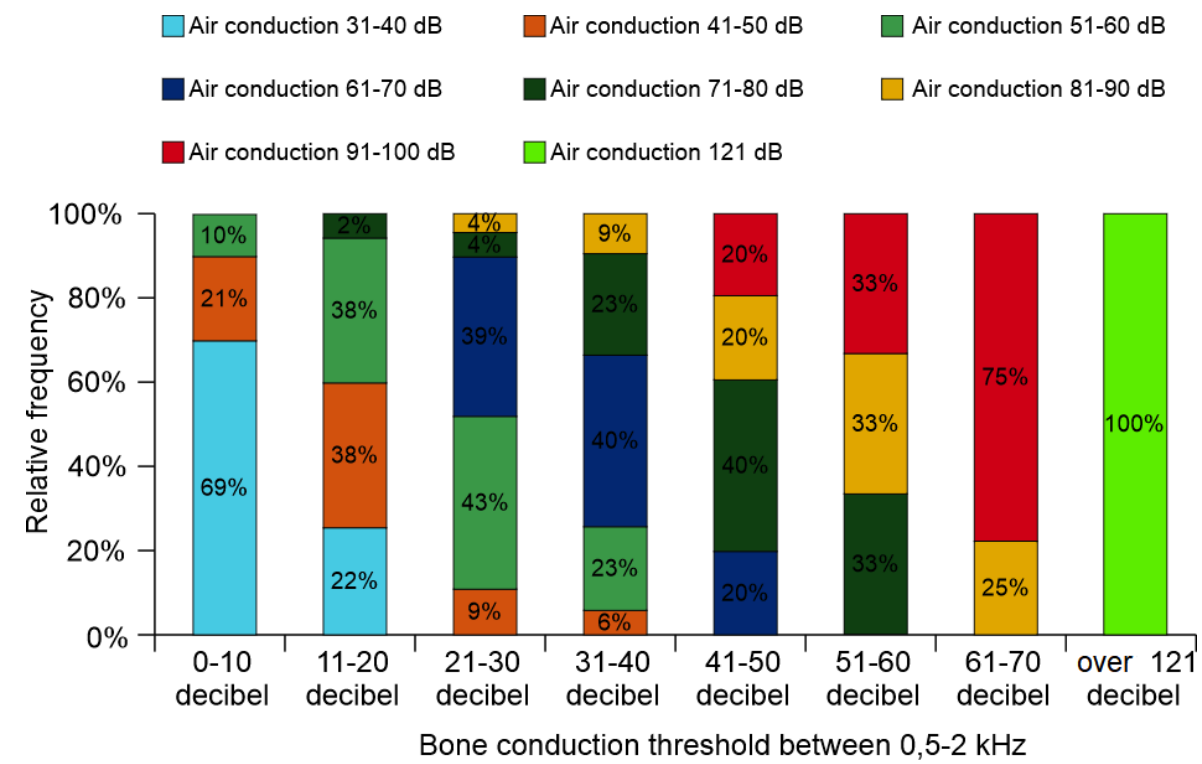

Figure 2. Pre-operative relative frequency of AHT vs. BCT for frequencies of 0.5-2 kHz. AHT, absolute hearing threshold; BCT, bone conduction threshold.

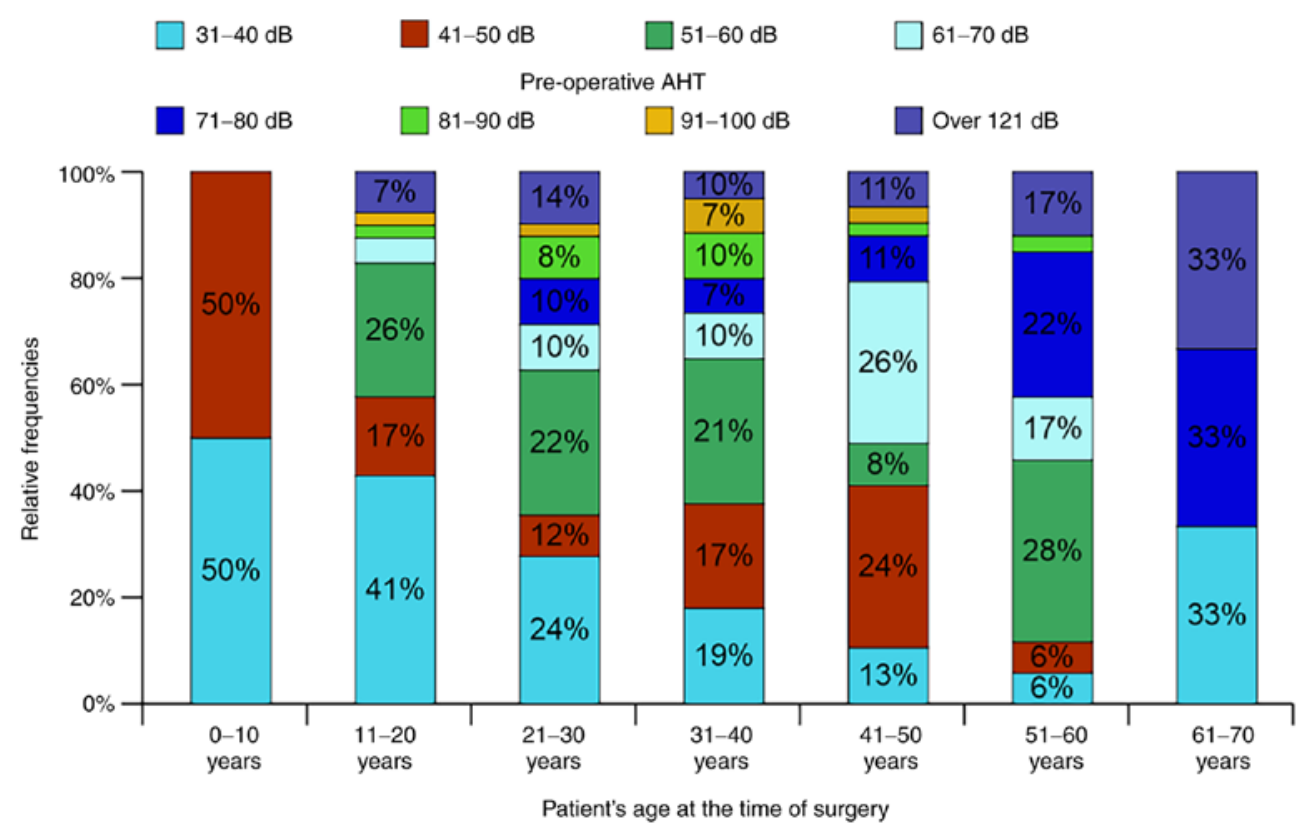

Figure 3. Influence of age group on distribution of relative frequency of pre-operative ATH. AHT, absolute hearing threshold. 


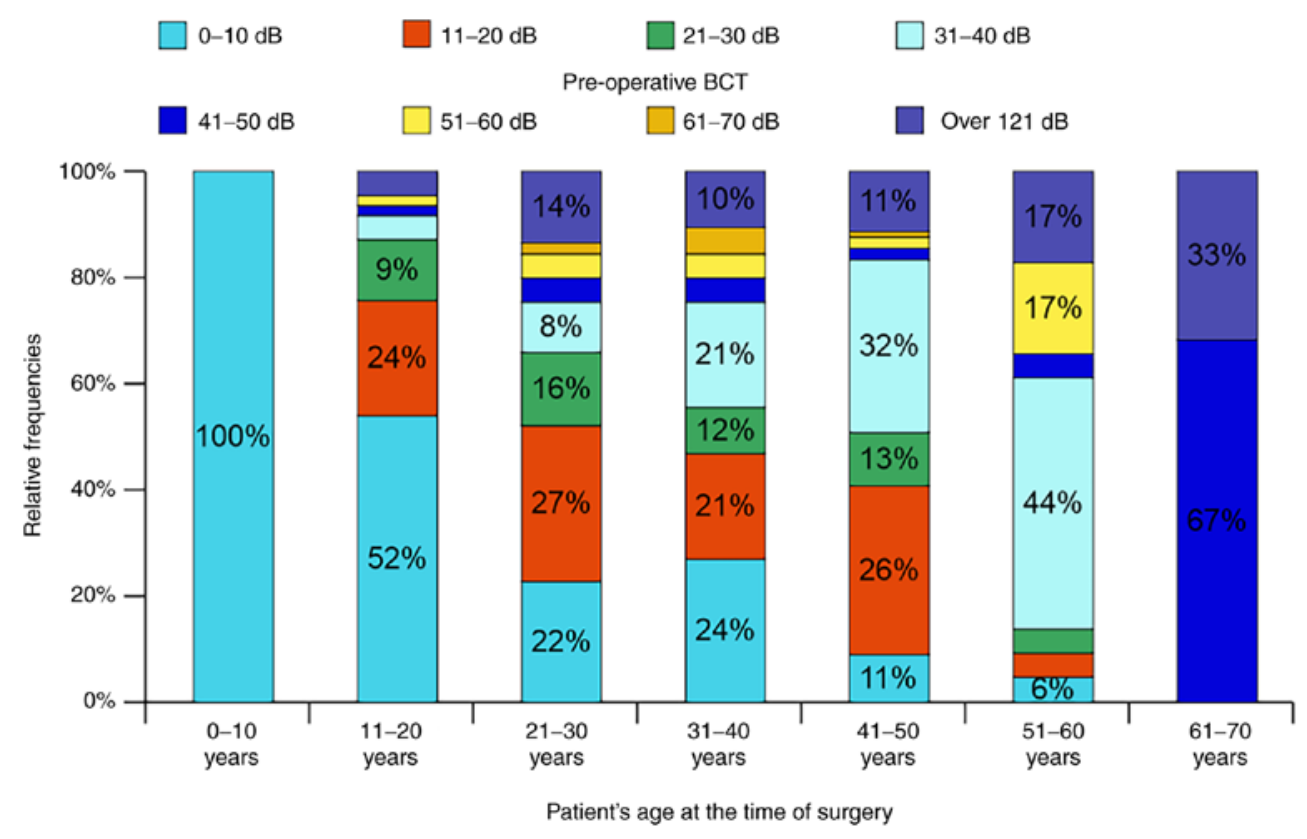

Figure 4. Influence of age group on distribution of relative frequency of pre-operative BCT. BCT, bone conduction threshold.

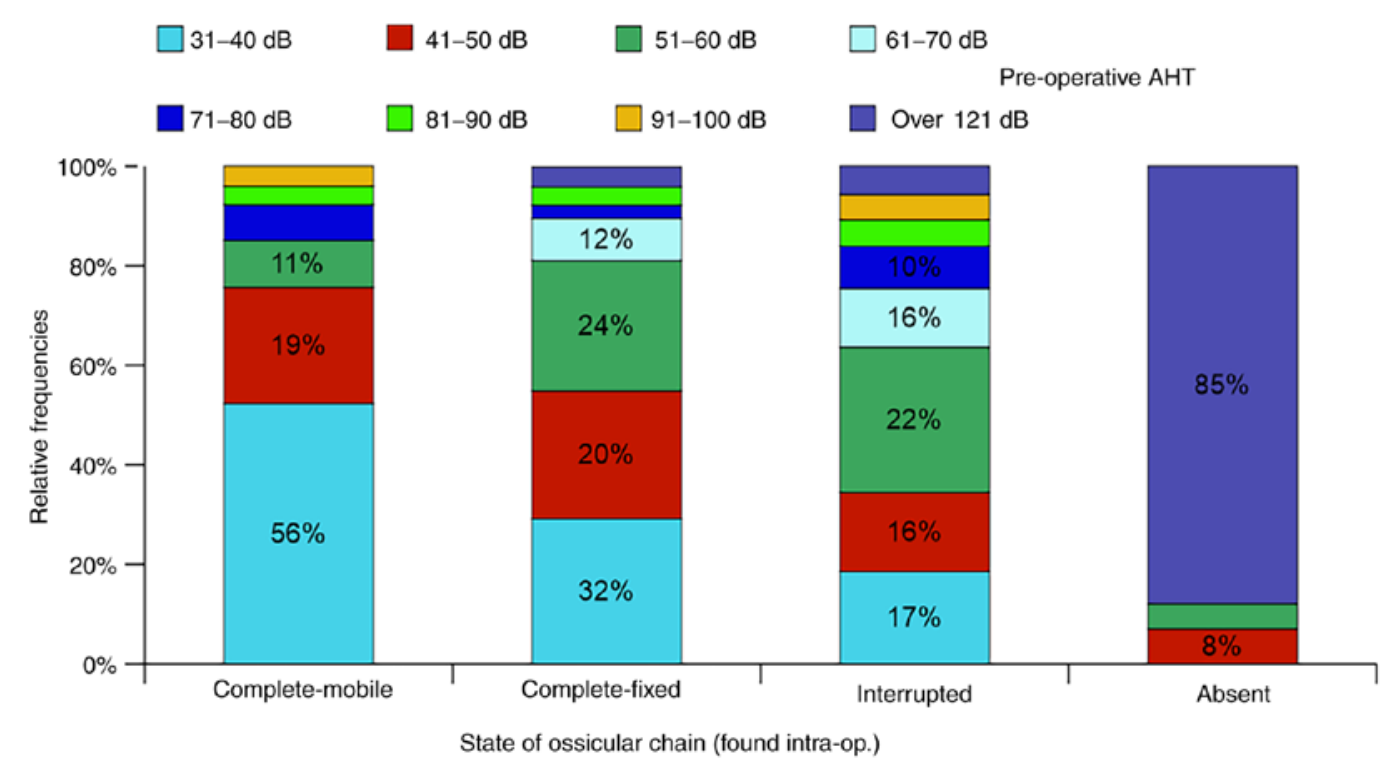

Figure 5. Influence of the OC status on the relative frequency of pre-operative AHT. OC, ossicular chain; AHT, absolute hearing threshold.

The clinical stage of disease, complicated or not complicated, proved to have direct analytical function connections to pre-op AHT distribution. It is obvious that the appearance of a complication signifies a certain degree of severity of the disease and therefore a larger number of permanently damaged mastoid cells (Fig. 8). By connecting the middle of each column from each series we obtain a graphic representation of two linear functions of opposing evolution trends.

Since the total lesional score is arbitrary, including all other lesions except for those of the middle-ear mucosa (protympanum, tympanic cavity, additus, antrum, mastoid and petrous cells), the findings shown in Fig. 9 regarding its impact on AHT distribution become similar to those of Fig. 8 .

\section{Results and Discussion}

Fig. 10 shows the global functional results at 1-year and 2 years post-operative, respectively, and we can observe a $3 \%$ loss rate in $\mathrm{BC}$ hearing and a $39.5 \%$ rate of gain while the rate of unmodified AHT (status quo ante) is $57.5 \%$. Two years after surgery, the rate of loss doubled, the rate of gain decreased to $31.5 \%$ and the status quo rate increased to $61.5 \%$ (Fig. 10).

It is paramount to note that the results at the end of the 2nd year remained unchanged for the entire period, up to 8.12 years which leads to the assumption that stable functional results for a mean period of 8 years could be predicted exclusively at the end of the cavity epithelization or, better still, 2 years post-operative. Thus, it becomes extremely useful to inform the patients and instruct them accordingly. Practically, 


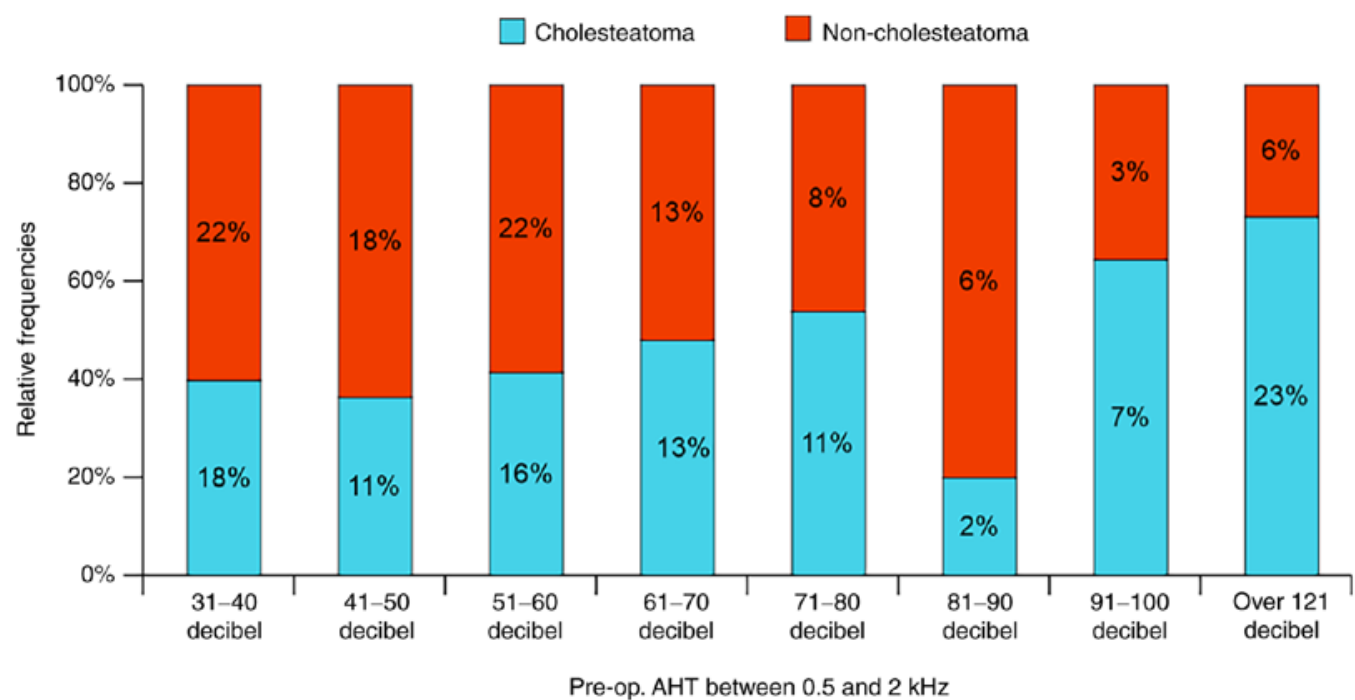

Figure 6. Influence of the type of disease (cholesteatoma vs. non-cholesteatoma) on the relative frequency of pre-operative AHT. AHT, absolute hearing threshold.

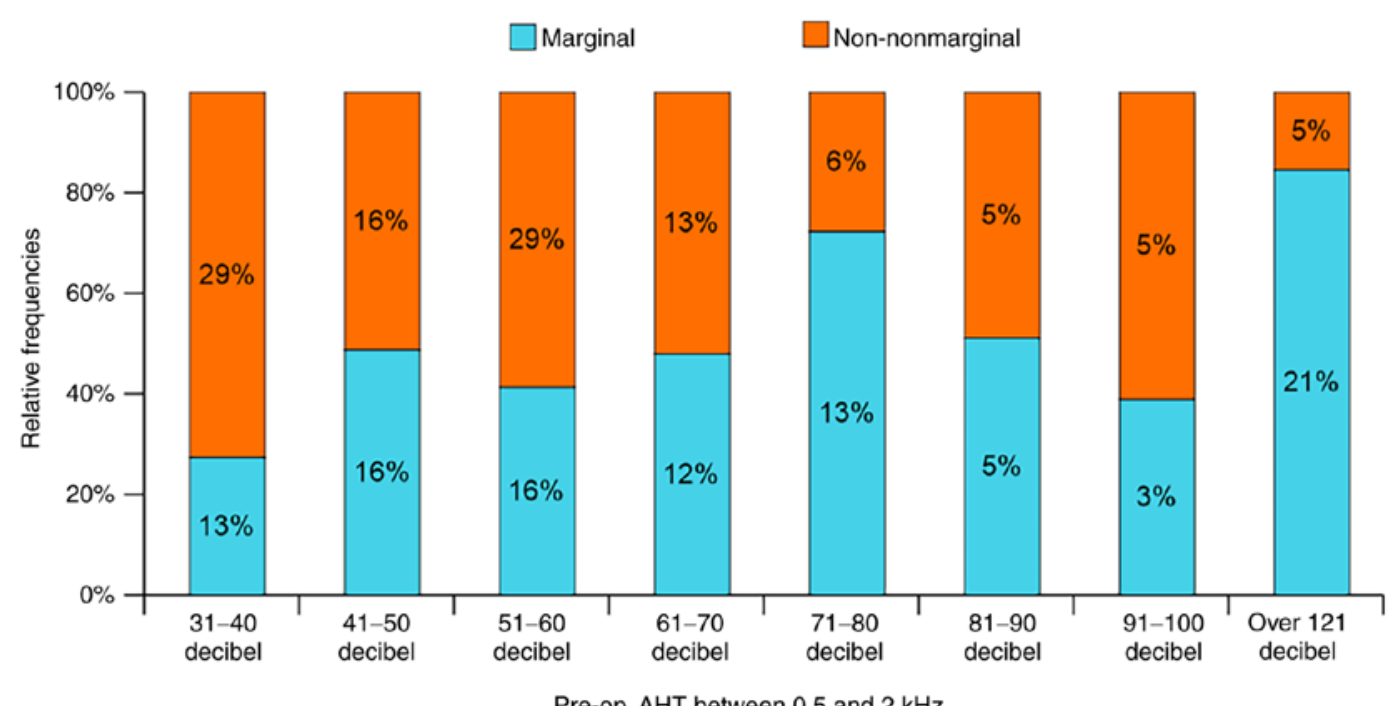

Figure 7. Influence of the type of TM perforation (marginal vs. non-marginal) on the relative frequency of pre-operative AHT. AHT, absolute hearing threshold.

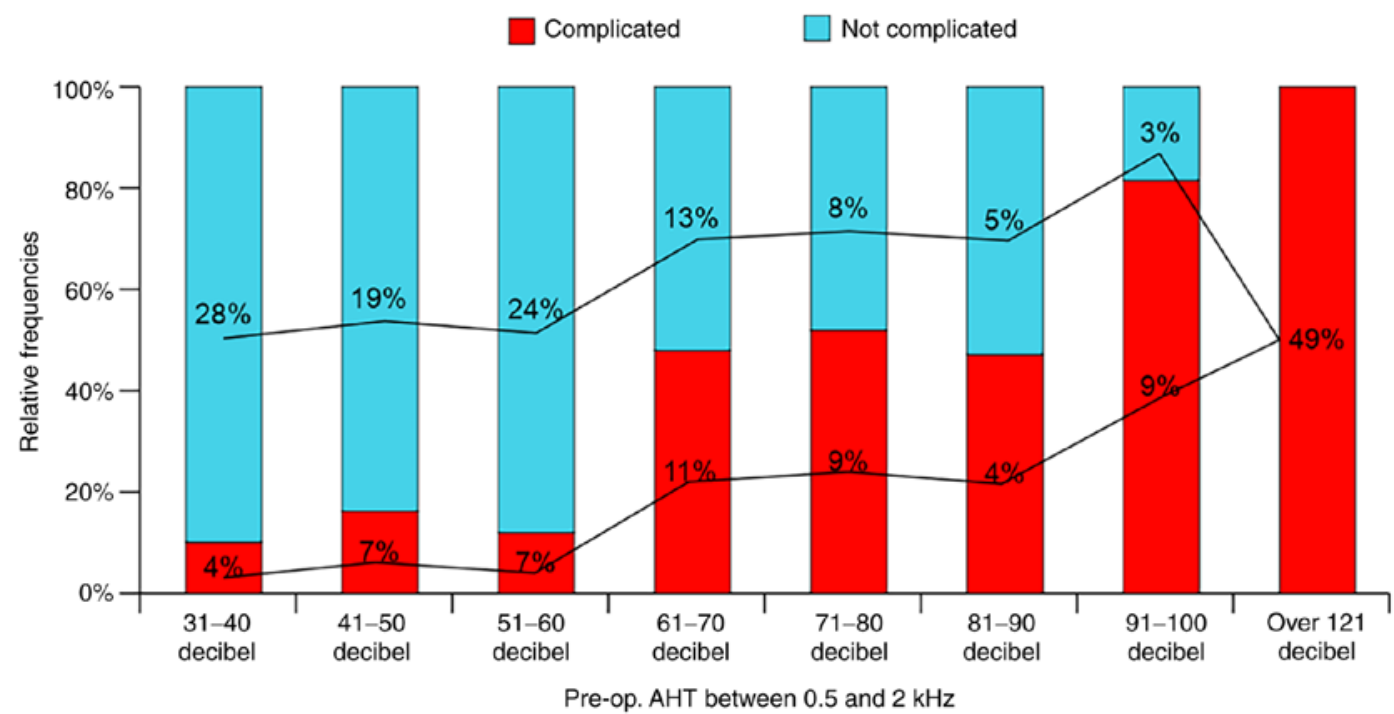

Figure 8. Influence of the clinical stage of disease (complicated vs. not complicated) on the relative frequency of pre-operative AHT. AHT, absolute hearing threshold. 


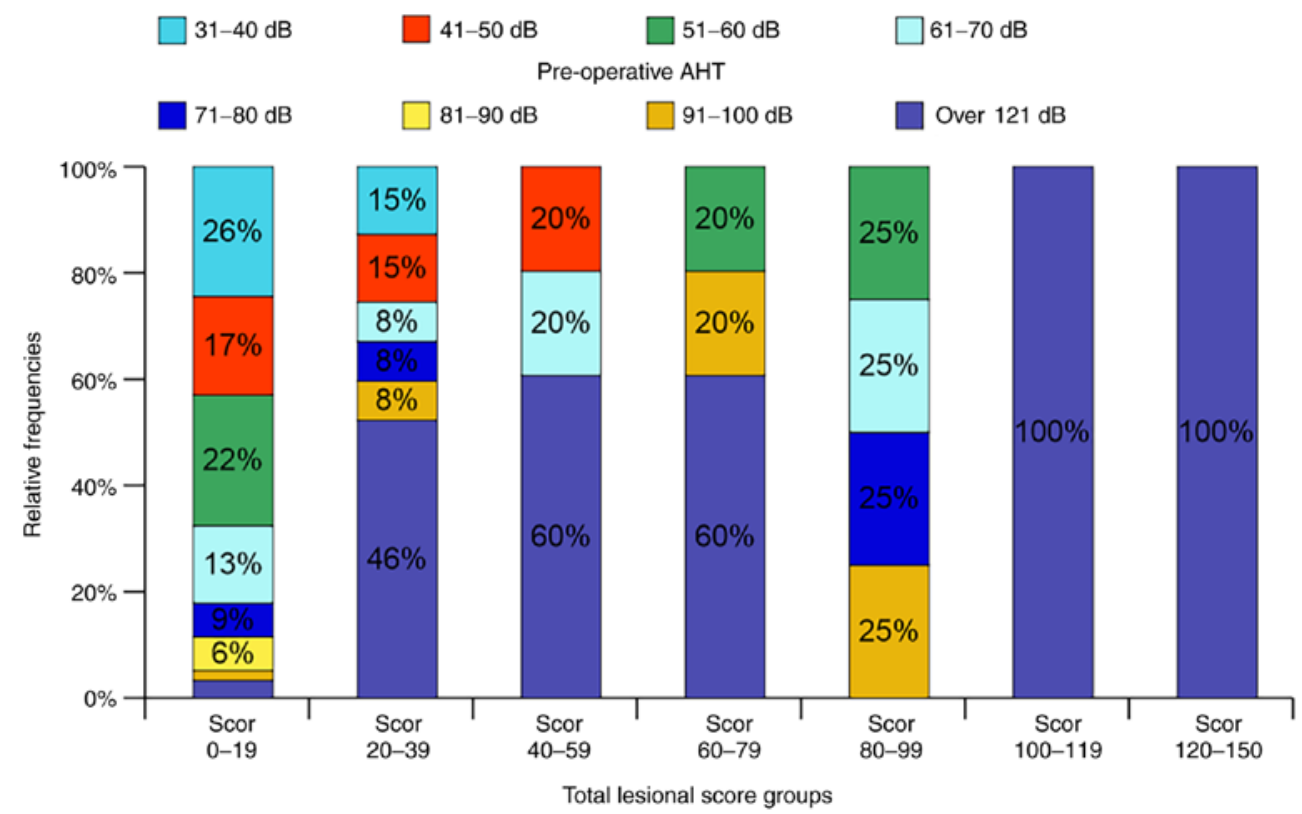

Figure 9. Influence of total lesion score on the relative frequency of pre-operative AHT. AHT, absolute hearing threshold.

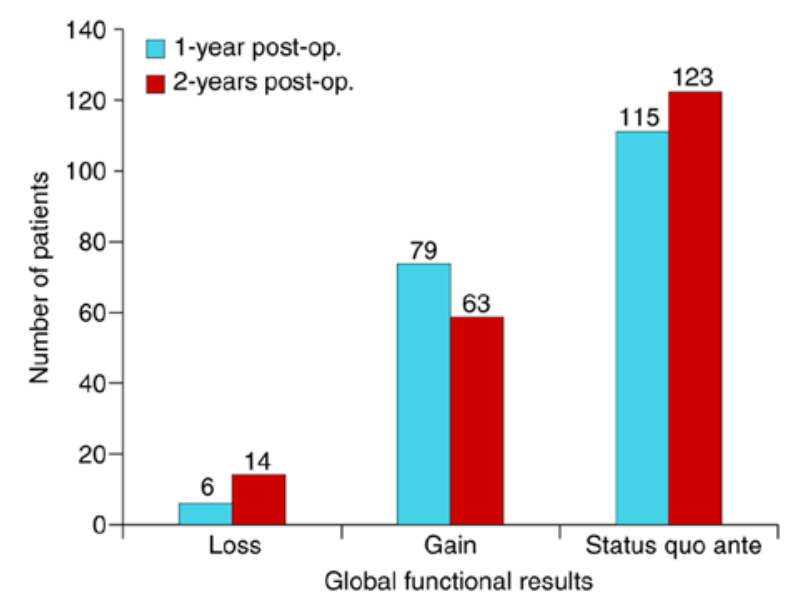

Figure 10. Global functional results at 1-year and 2-years post-operative.

the audiogram at 2 months (complete epithelization in $80 \%$ of cases) should not be repeated earlier than 10-22 months post-operative. As for expressing the functional results in absolute values $(\mathrm{dB})$ we can see from Fig. 11 that the null value (status quo ante) was observed in $61.5 \%(\mathrm{n}=123)$ of the cases, the most drastic loss of $60 \mathrm{~dB}$ in $0.5 \%(\mathrm{n}=1), 20-30 \mathrm{~dB}$ loss in $2.5 \%(\mathrm{n}=5), 10 \mathrm{~dB}$ loss in $4 \%(\mathrm{n}=8) ; 10-20 \mathrm{~dB}$ gain in $17 \%$ $(\mathrm{n}=34) ; 25-35 \mathrm{~dB}$ gain in $12.5 \%(\mathrm{n}=25)$ and the best gain of $40 \mathrm{~dB}$ in $2 \%(\mathrm{n}=4)$ of the patients.

From a practical standpoint, we defined the most adequate pre- and post-operative terms that could give us expectancy about the functional results. What can we most definitely know before surgery?-Age of patient, clinical stage of disease (complicated, not complicated), type of disease (cholesteatoma, non-cholesteatoma), type of TM perforation (marginal, central), radiographic configuration, AHT between $0.5-2 \mathrm{kHz}$ (still, a subjective examination), BCT between $0.5-2 \mathrm{kHz}$. What can we discover during surgery?-OC status, total lesional score (extent of lesions), type of mastoidectomy (radical, modified radical). Our statistical analysis led us to a number of conclusions.

For the complicated cases, mastoidectomy did not lead to hearing threshold gain but provided hearing preservation in $93 \%$ of the cases ( 42 out of the 45 patients). In non-complicated cases, a gain occurred in $41 \%$ (63 of the 155 patients) which was $10 \%$ higher than the global gain rate shown in Fig. 10. The status quo ante occurred in $52 \%$ (81 out of 155) of the patients (Fig. 12). Regardless of the state of the disease, loss of hearing occurred in $7 \%$ ( 3 of 45 and 11 of 155 , respectively). This rate was found to be identical to the mean global rate of hearing loss (Fig. 10). Of interest, the authors of the present study intend to publish a subsequent study on the anatomic (drainage) results of the same cohort, which will further explain the present data.

For cholesteatoma, the gain rate was $16 \%$ lower than that for non-cholesteatoma and the hearing loss rate was $2 \%$ higher (and 3\% higher than the mean global rate) which provided a consistent prognostic signification for gain but not for hearing loss probability (Fig. 13).

The influence of TM perforation as a predictive factor was inconsistent and not as clear as for cholesteatoma, although the numeric values could lead to a negative prognosis in the case of marginal perforations (Fig. 14).

While the connection between the type of disease and functional results is a statistical one (indirect) in which an intermediate term could be suspected as dependent on the clinical forms of disease, the connection to the patient's age and pre-operative hearing thresholds was direct (cause-effect or analytical function) (Figs. 15-17). We therefore conclude that these are the fundamental prediction factors for functional results in mastoidectomy. All three charts show linear analytical functions with characteristic evolution trends. Thus, positive functional results were inversely proportional to age and pre-operative hearing thresholds (descending trend) while the indifferent and negative results were directly proportional to these parameters (ascending trend). 


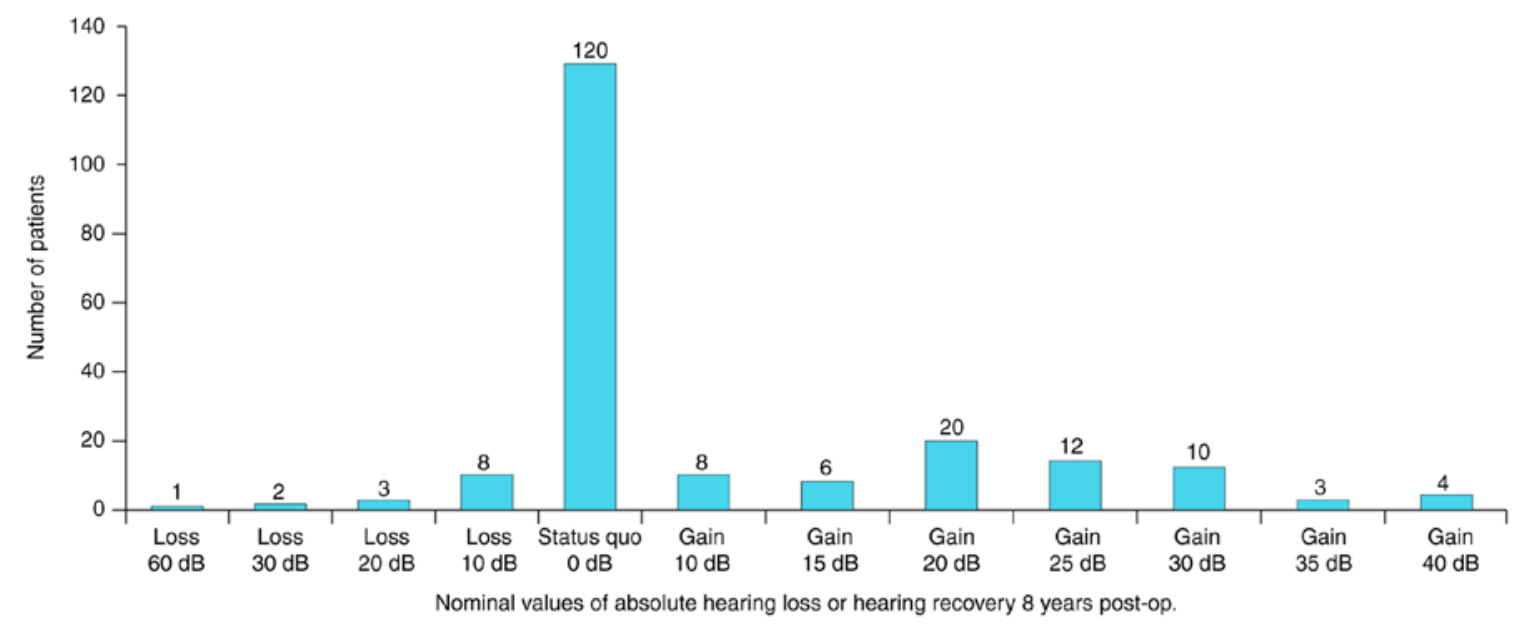

Figure 11. Global functional results at 8-years post-op (nominal values of absolute hearing loss or hearing gain).

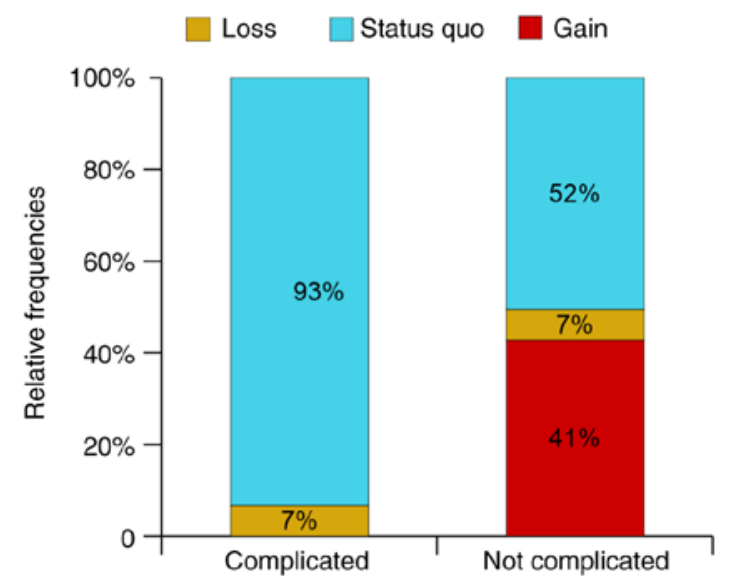

Clinical stage of disease (presence or absence of complications)

Figure 12. Influence of the clinical stage of disease (complicated vs. not complicated) on the functional results.

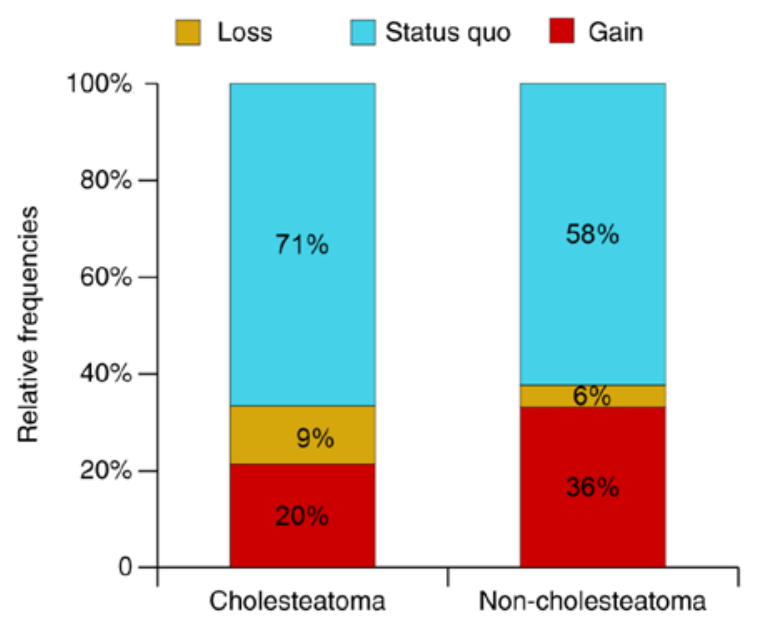

Type of disease (presence or absence of cholesteatoma)

Figure 13. Influence of the type of disease (cholesteatoma vs. non-cholesteatoma) on the functional results.

This represents an experimental confirmation of theoretical facts previously stated; to obtain the optimal functional results,

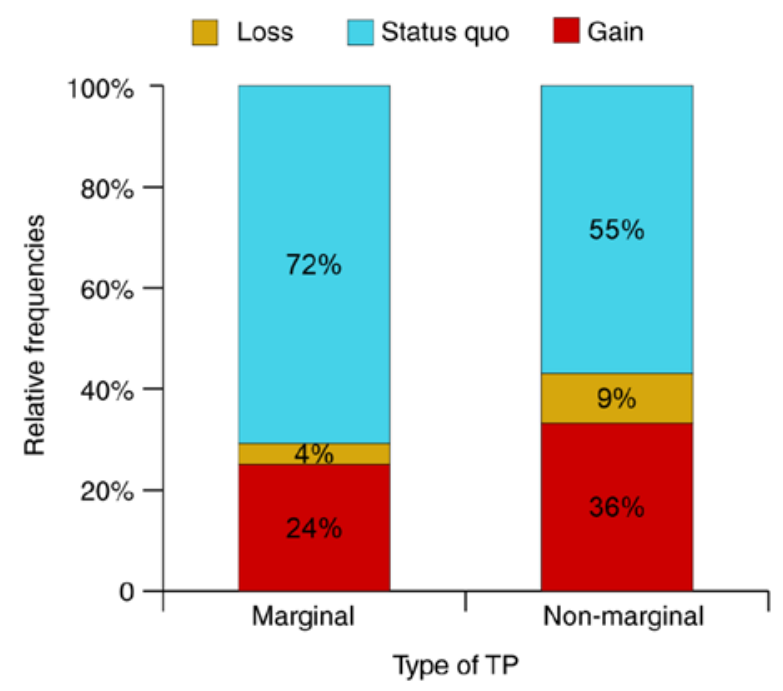

Figure 14. Influence of the type of TP (marginal vs. non-marginal) on the functional results. TP, tempanic perforation.

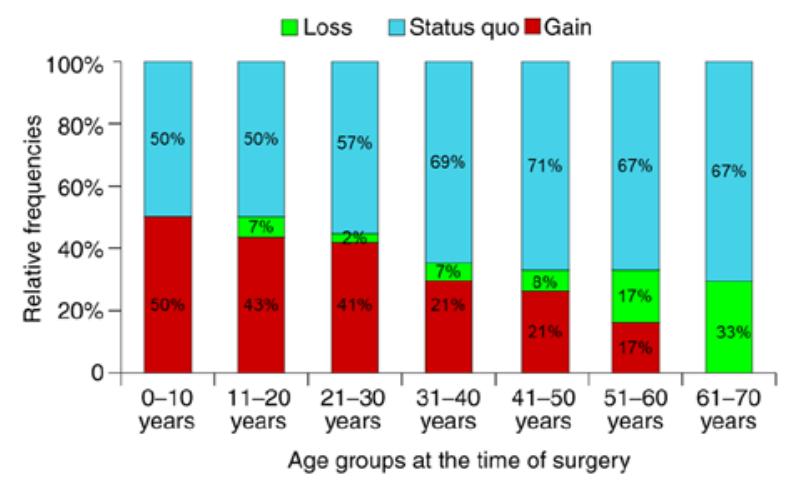

Figure 15. Influence of age on the functional results.

the surgery must take place long before complications occur or as long as hearing thresholds remain permissive for gain. Ultimately, the threshold dictates the prognostic of functional gain.

The OC acts as a double standard for prognostic value since the gain is apparently inexplicably good for interrupted or missing OC (Fig. 18). 


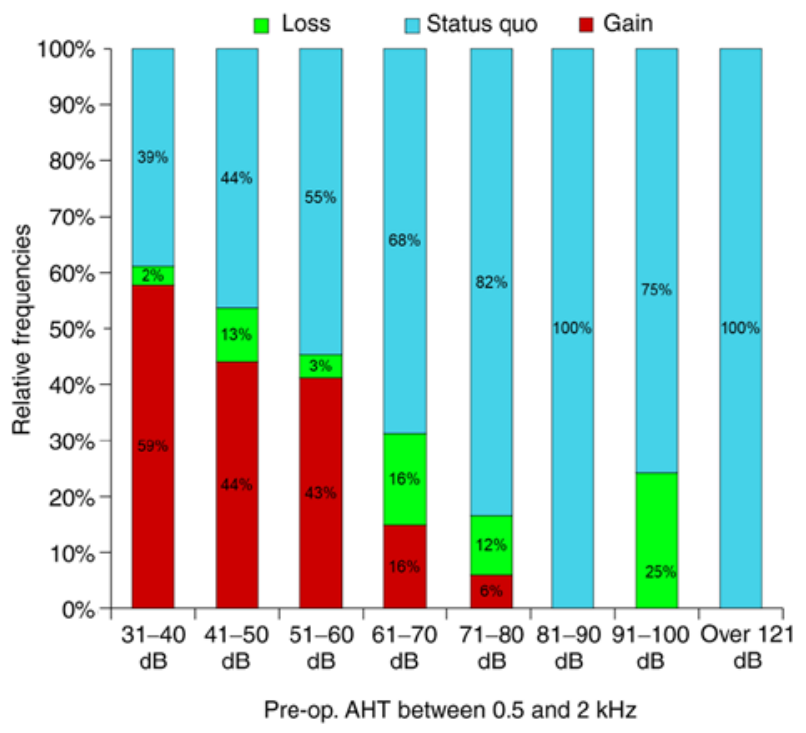

Figure 16. Influence of pre-operative AHT on the functional results. AHT, absolute hearing threshold.

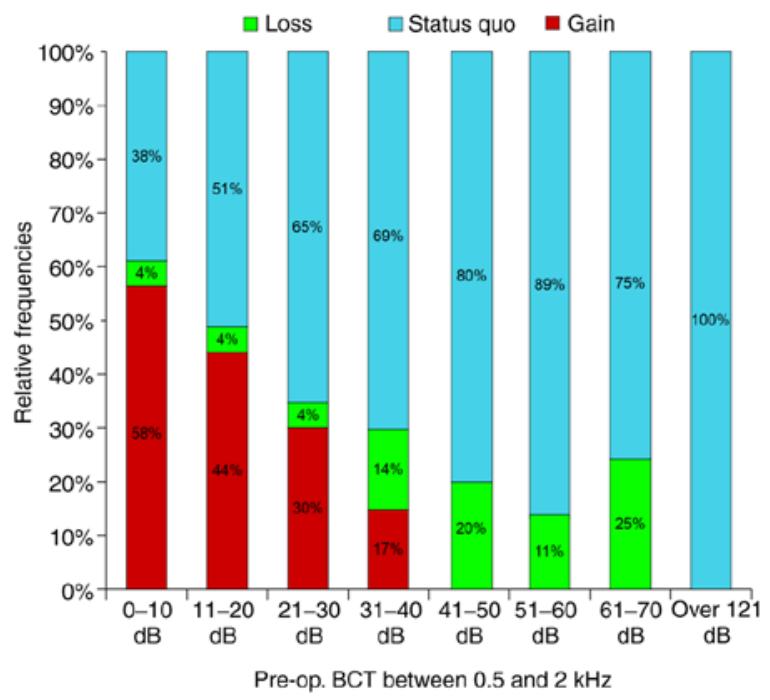

Figure 17. Influence of pre-operative BCT on the functional results. BCT, bone conduction threshold.

Since the total lesional score has been previously discussed (14) and is arbitrary, its influence on functional results is coherent to the theoretical statement that the intensity of disease is correlated to the specific weight of the lesional cells (low score mean small proportion of afflicted cells) (Fig. 19).

The influence of the type of surgery contradicts neither theoretical or intuitive considerations and revealed a double rate of gain for radical modified mastoidectomy compared to radical mastoidectomy (Fig. 20). A similar study by Galm et al compared the functional results [pre- and post-operative air-bone gap (ABG)] for opened and closed technique mastoidectomy and found no statistically significant differences. A closed technique has the advantage of preserving the posterior wall and making the ear 'water proof'. The post-operative ABG was $\leq 20 \mathrm{~dB}$ in $41 \%$ of patients with closed mastoidectomy and $21 \%$ in patients with opened technique (15). The results were

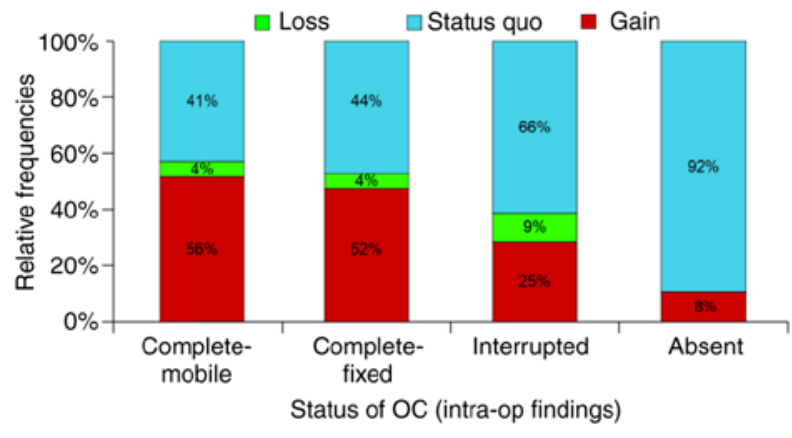

Figure 18. Influence of the OC status on the functional results.

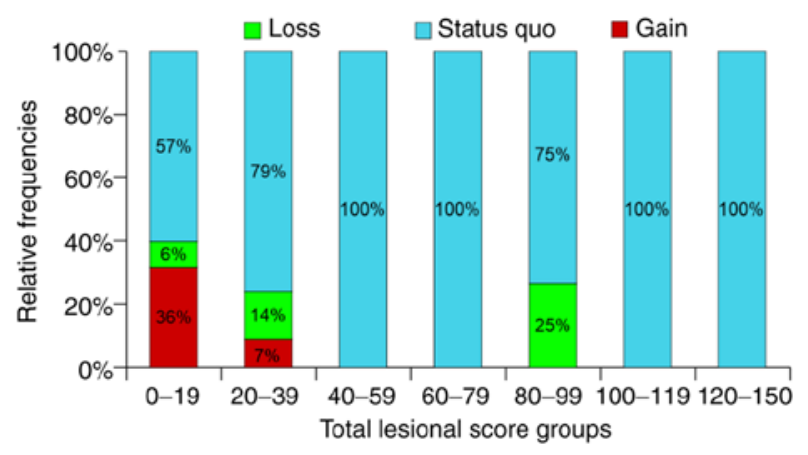

Figure 19. Influence of the total lesion score on the functional results.

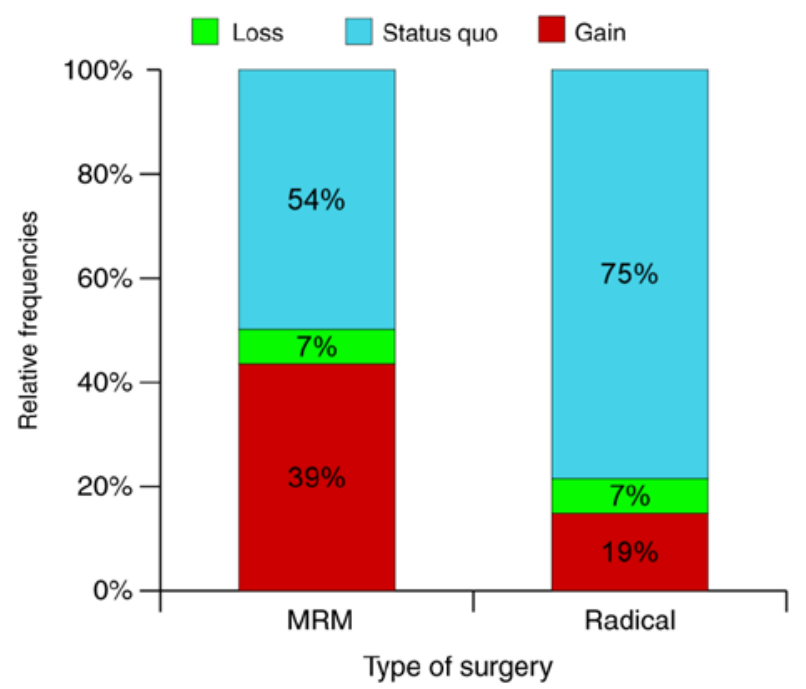

Figure 20. Influence of the type of surgery (radical vs. MRM) on the functional results. MRM, modified radical mastoidectomy.

also considered comparable to those of Stankovic (16) and Lucidi et al (17) as the authors consider it feasible to achieve good functional results with both techniques. The main limitation of this study is that it did not benefit from long-term hearing results.

The success rate of the mastoidectomy is the most important factor for the functional state of an operated ME and is congruent to the gain rate (Fig. 21). Failed drainage means remnant lesions and therefore poor functional results. The two types of results (drainage and hearing gain) are two aspects of the same phenomena. The codes 


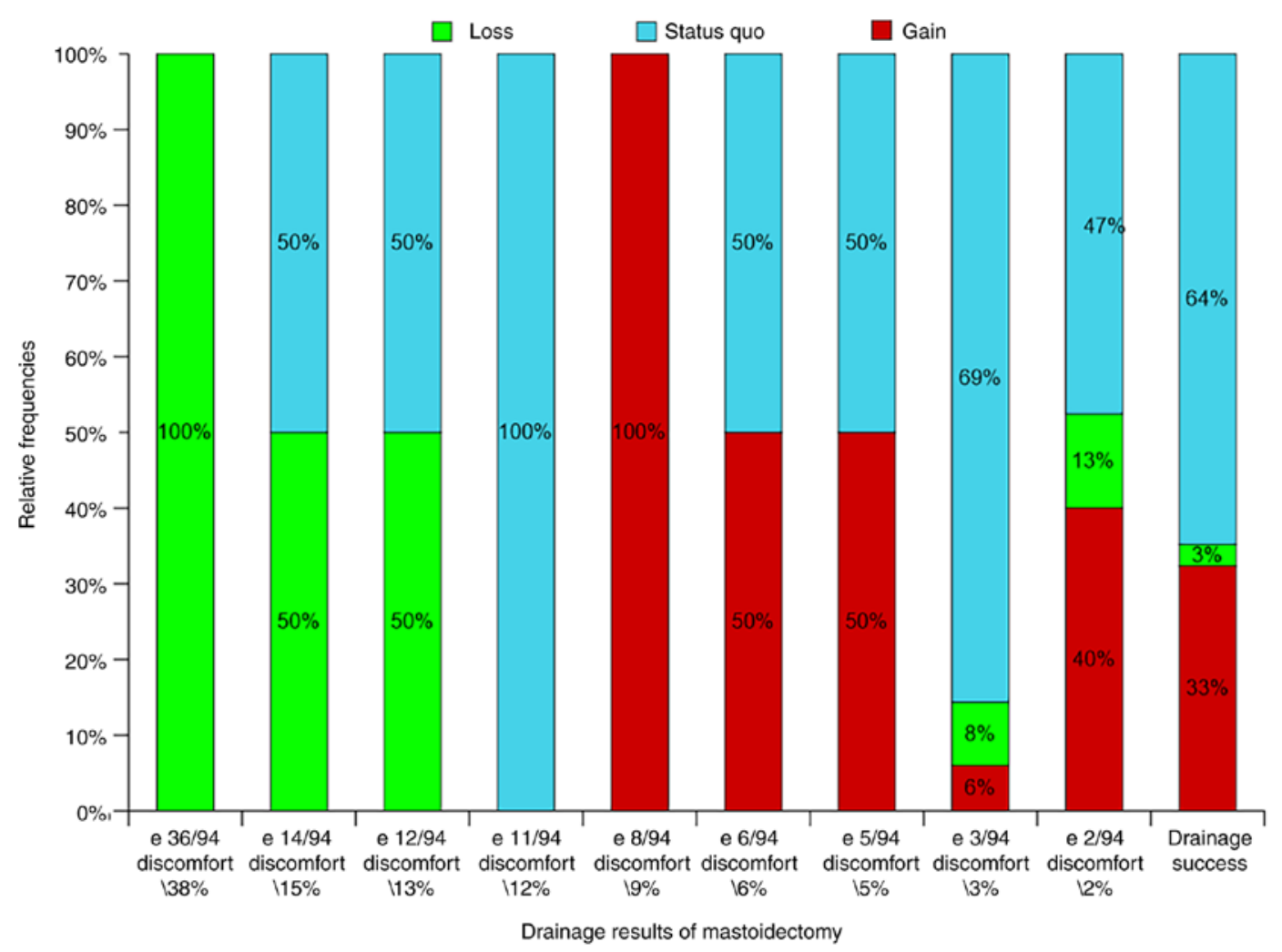

Figure 21. Influence of the drainage results of surgery on the functional results.

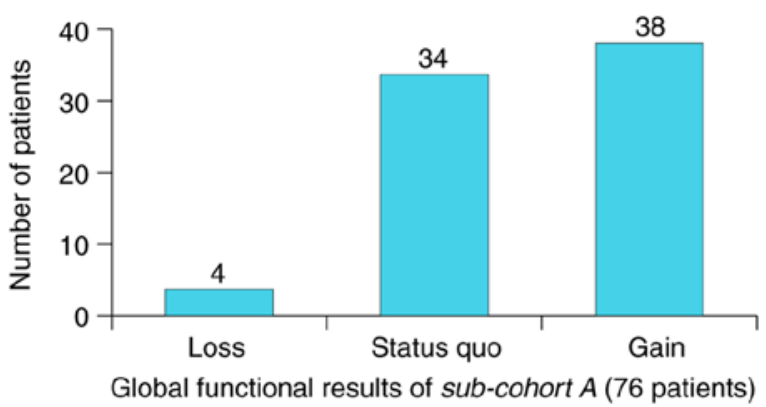

Figure 22. Global functional results of sub-cohort A (76 patients filtered by favorable hearing threshold prognostic criteria).

presented in Fig. 21 represent our own original quantification of drainage results of mastoidectomy as related to the number of discharge episodes and therefore to the degree of comfort/discomfort of the patient. We intend to present our results in a future article concerning the drainage long-term results of the same cohort of patients and to further discuss this system of defining parameters.

To further confirm our conclusion, we filtered the analyzed cohort $(n=200)$ by several parameters. First, we filtered the patients by pre-operative hearing thresholds, the criteria being AHT up to $50 \mathrm{~dB}$ correlated to BCT up to $30 \mathrm{~dB}$. We gathered a sub-cohort A of 76 patients who showed significant change in functional results: Gain rate $50 \%$, loss rate $5 \%$, status quo $45 \%$ (Fig. 22). The second criteria, age up to 50 , provided us a new sub-cohort B of 62 patients (filtered by both hearing threshold and age) with an increased gain rate of $56 \%$, an unaltered loss rate of $5 \%$

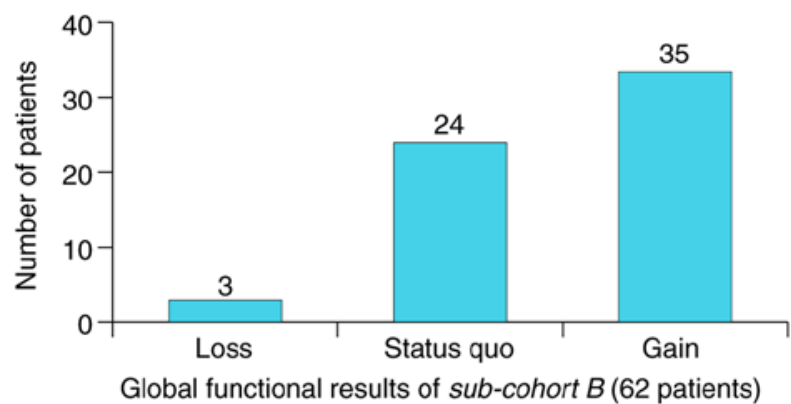

Figure 23. Global functional results of sub-cohort B (62 patients filtered by favorable hearing threshold prognostic criteria and age).

and a decreased status quo of 39\%. Functional results in absolute values (dB) for sub-cohort B are shown in Fig. 23 where we can observe that the maximum value for hearing loss $(10 \mathrm{~dB})$ is present in $5 \%$ of the patients $(\mathrm{n}=3)$, status quo $(0 \mathrm{~dB})$ in $39 \%(\mathrm{n}=24)$ and gain as follows: $10 \mathrm{~dB}$ in $2 \%$ $(\mathrm{n}=1), 15 \mathrm{~dB}$ in $5 \%(\mathrm{n}=3), 20 \mathrm{~dB}$ in $21 \%(\mathrm{n}=13), 25 \mathrm{~dB}$ in $16 \%$ $(n=10), 30 \mathrm{~dB}$ in $8 \%(\mathrm{n}=5), 35 \mathrm{~dB}$ in $2 \%(\mathrm{n}=1)$ and $40 \mathrm{~dB}$ in $3 \%(\mathrm{n}=2)$. We can also note the distribution of recovery results by the normal law of probability represented by the Gaussian bell curve with a central axis at the mean value of $20 \mathrm{~dB}$ (Fig. 24).

Functional results for the same sub-cohort B depending on the type of surgery (in absolute and relative frequencies) are presented in Figs. 25 and 26. For absolute values (number of patients), the results are apparently paradoxical; hearing loss appears exclusively in MRM but the explanation is rather simple since a partial surgery increases the chances of remnant 


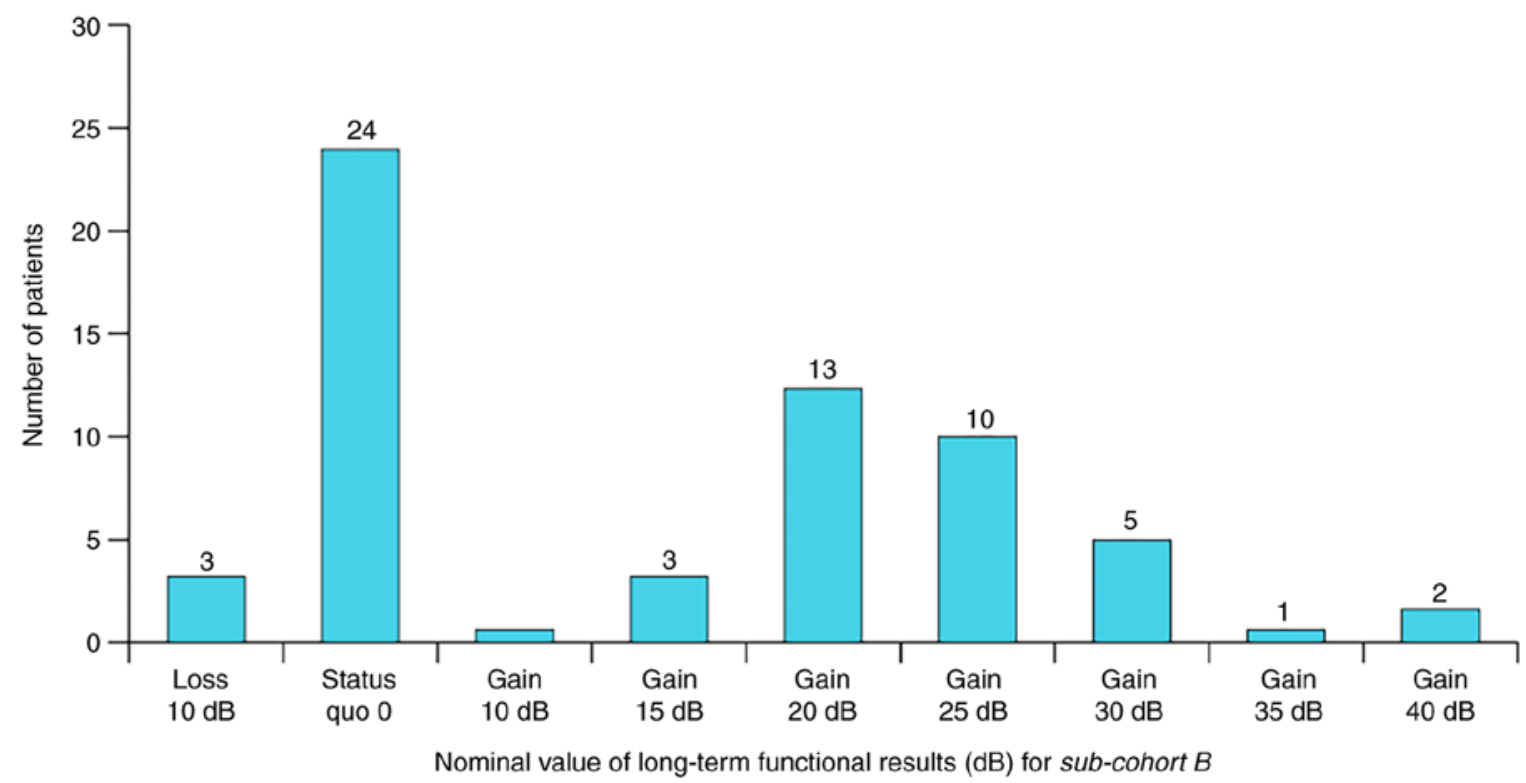

Figure 24. Nominal value of long-term functional results for sub-cohort B.

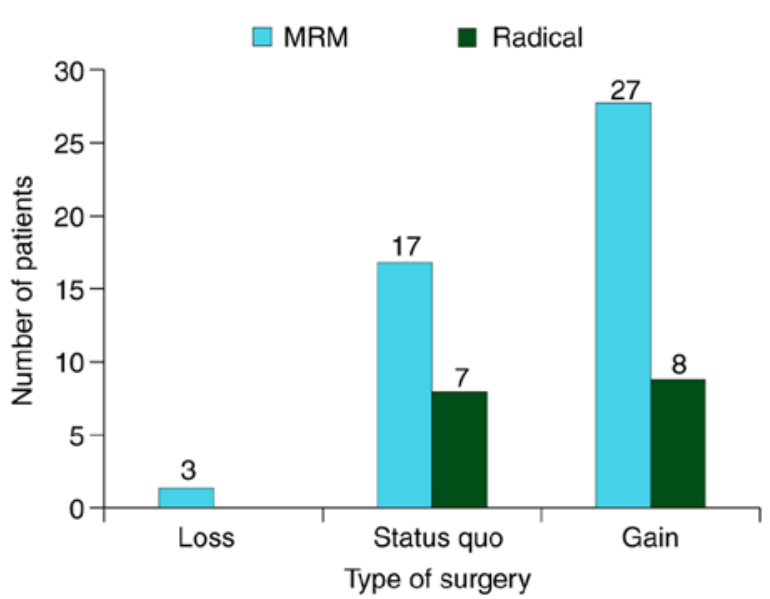

Figure 25. Influence of type of surgery (radical vs. MRM) on the functional results for sub-cohort B (absolute values).

lesions. For the relative frequencies the distribution was similar in both types of surgery which signified the intrinsic property of the surgery to determine well-defined functional results. All is perfectly explainable from a theoretic and intuitive point of view since mastoidectomy means exclusion of lesions and lesions manifest themselves, ultimately, by hearing loss. The functional results depend on the chance of maximum lesion exclusion.

The influence of the $\mathrm{OC}$ on the functional results within sub-cohort B were in accordance to our previous results which state that it can only partially explain the functional status of the ME. We should however note the high gain rate for intact OC [81\% ( $\mathrm{n}=13)]$ when mobile and [75\% ( $\mathrm{n}=9)]$ when fixated (Figs. 27 and 28). This only confirms the statement that the intensity of the disease is determined by the proportion of lesions; the $\mathrm{OC}$ responds to the presence of disease by fixation and osteolysis.

The nervus probandi of our entire study is still the relationship between drainage and the functional results of mastoidectomy. These are the expression of the same mass

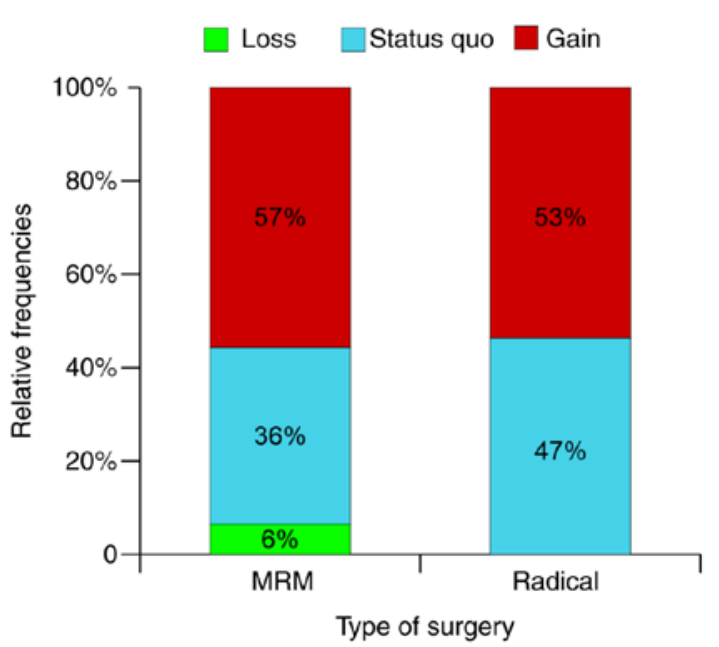

Figure 26. Influence of type of surgery (radical vs. MRM) on the functional results for sub-cohort B (relative values).

random phenomenon. From this perspective, mastoidectomy represent a direct intervention in a static population in which stochastic processes apply. We observed that hearing gain was characterized by a rate of drainage success of $83 \%$ which means that the proportion of remnant cells with irreversible lesions was contained within the defining interval of healthy ME mucosa. A status quo was obtained with a $79 \%$ drainage success while loss of hearing was characterized by a relatively high (67\%) degree of drainage failure (3 episodes of discharge over 94 months; 3\% discomfort) (Figs. 29 and 30).

In comparison, Mukherjee et al conducted a study on 133 MRM patients and published long-term results. Their conclusions were that MRM allows excellent visualization and has far lower residual rates than intact canal (ICW) wall procedures. A total of $61 \%$ of the patients had post-operative AC thresholds within $10 \mathrm{~dB}$ of the pre-operative values; $23 \%$ showed worsening and $16 \%$ improved, which was consistent to our functional results (5). 


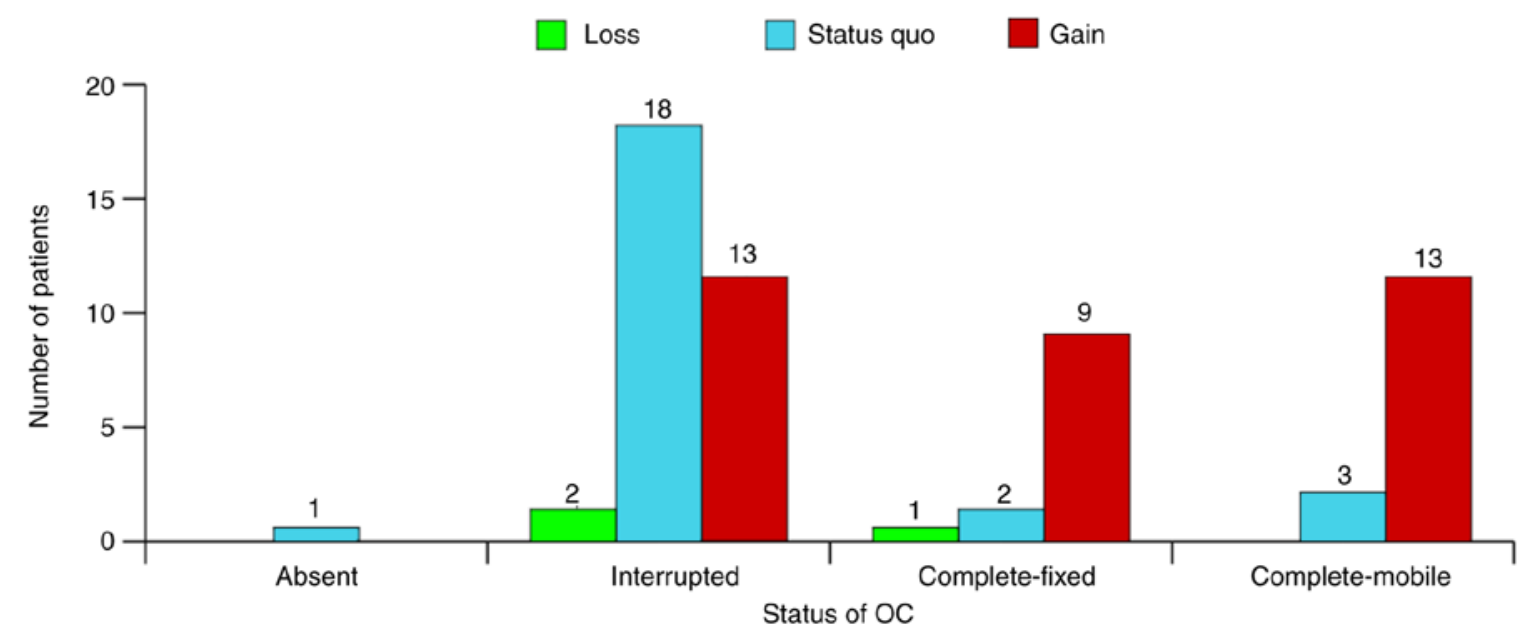

Figure 27. Influence of OC status on functional results for sub-cohort B (absolute values).

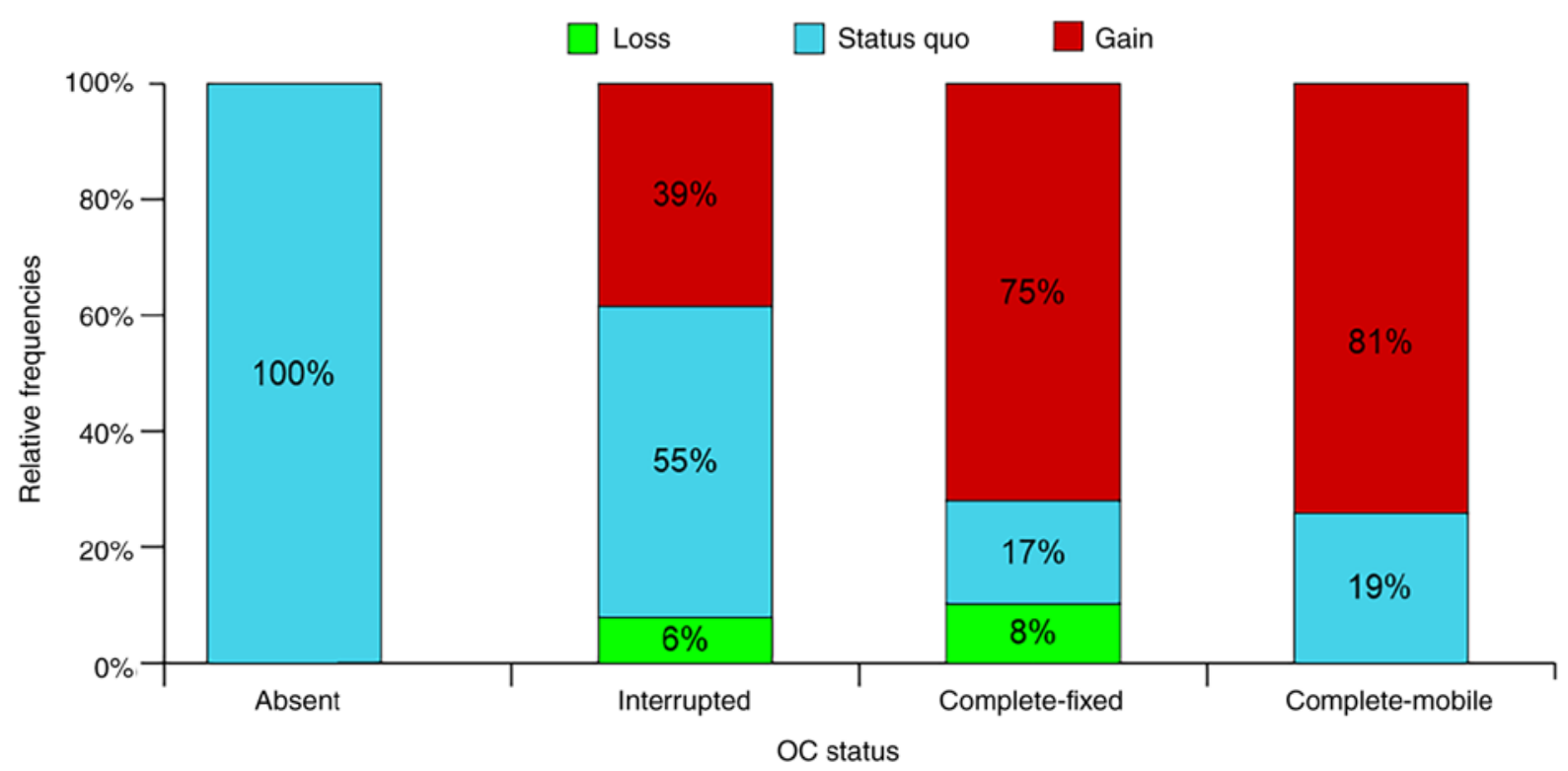

Figure 28. Influence of OC status on functional results for sub-cohort B (relative values). OC, ossicular chain.

A smaller study by Çetinkaya et al reported the results of 30 patients with various types of mastoidectomies as follows: $85 \%$ hearing gain of $5-35 \mathrm{~dB}, 10 \%$ hearing loss and $3 \%$ status quo ante (3).

The much more extensive study by Kos et al analysed 259 cases of CWD mastoidectomy by measuring 4-frequency $(0.5,1,2$ and $4 \mathrm{kHz})$ average $\mathrm{ABG}$ and mean $\mathrm{AC}$ threshold. After revision tympanoplasty, the long-term results were unchanged or improved for $72 \%$ of the patients (18). These results were congruent to those reported by others (19-27).

A truly similar study is one performed by Pareschi et al that reported long-term functional results (10-year follow-up) and used the pure-tone average air conduction threshold (aPTA) instead of ABG that provides no information on the real hearing status (28). The functional results reported were $36.4 \%$ with aPTA $<30 \mathrm{~dB}$, similar to Vartiainen (29) with $38.8 \%$ aPTA $<40 \mathrm{~dB}$ at 10 years (not accounting for the $4 \mathrm{kHz}$ region) and to other studies with aPTA ranging from 31.2 to $42.4 \mathrm{~dB}$ with only 5 years post-operative (29-32).
In conclusion, good functional results cannot be achieved without good drainage results of the surgery. Even more, a successful drainage ensures long-term stability of hearing. The two types of results (drainage and functional) of mastoidectomy are expressions of the same phenomenon defined as a conversion of a static population by binary division in respect to the spatial distribution of its constituting units.

Functional results are linked by an analytical function to the intensity of the disease (pre-operative AHT and BCT) and length of evolution (age of patient). These parameters vary inversely proportional and can be considered as complete and precise analytical instruments for both functional and drainage results of mastoidectomy.

The global rate of hearing loss after surgery was $7 \%$, the global rate of gain was $32 \%$ and the rate of status quo ante was $61 \%$.

The favorable prognostic terms for good functional results include: AHT under $50 \mathrm{~dB}$, BCT under $30 \mathrm{~dB}$ and age under 


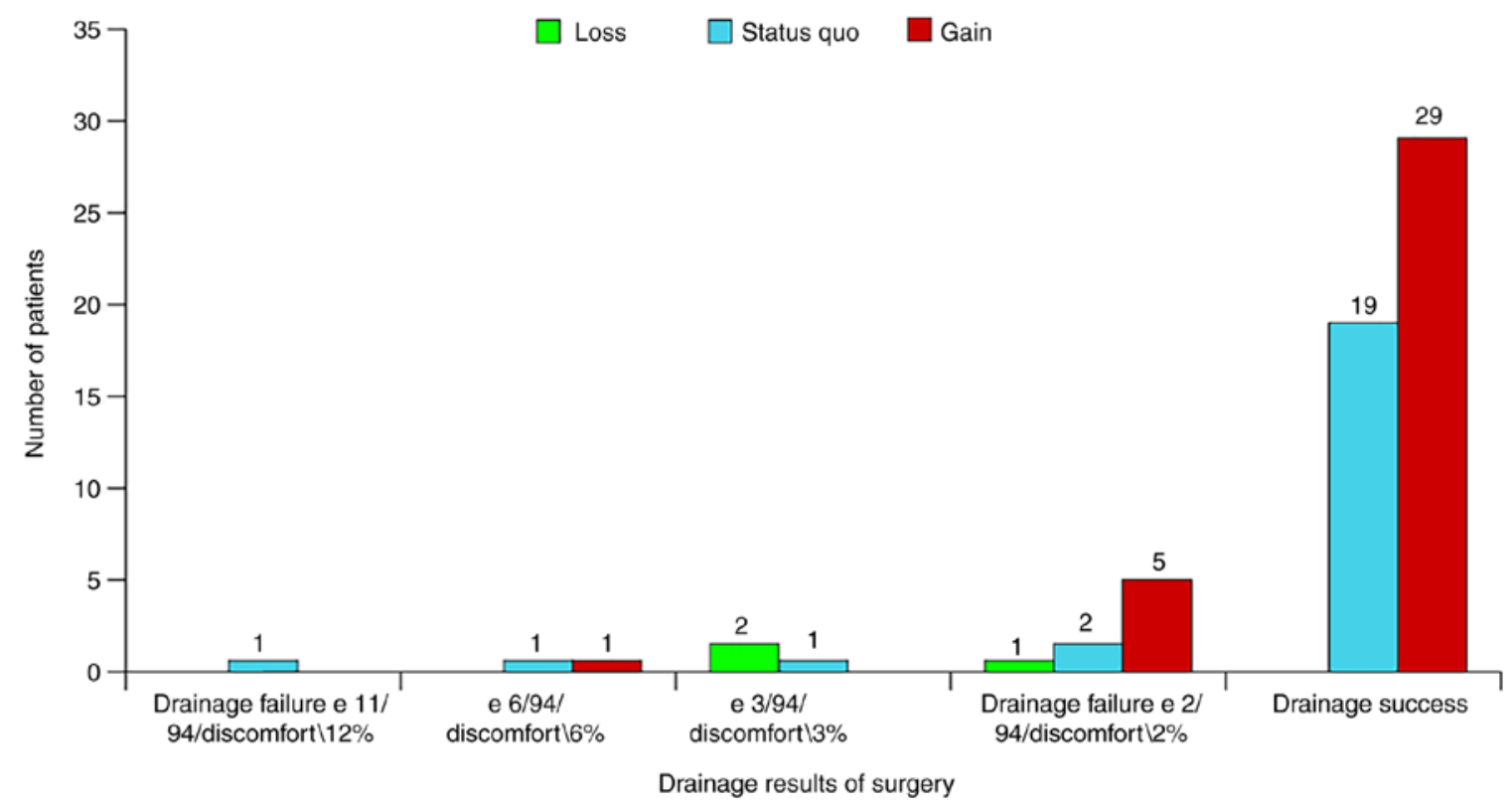

Figure 29. Influence of drainage results on the functional results for sub-cohort B (absolute values).

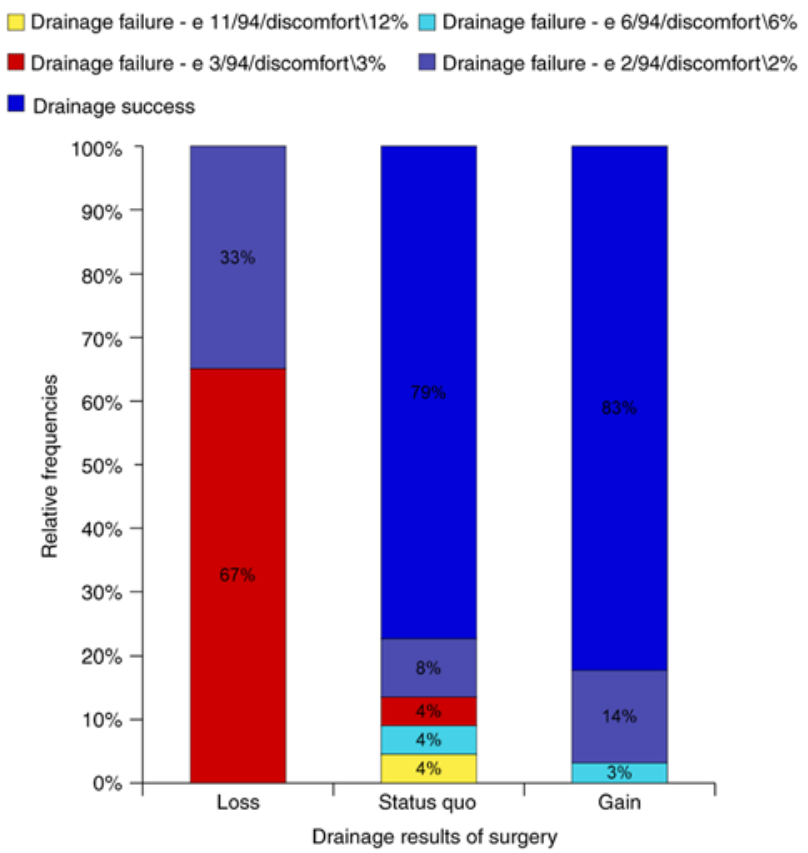

Figure 30. Influence of drainage results on the functional results for sub-cohort B (relative values).

50. When all these are present, the gain rate increased to $56 \%$ and the hearing loss rate decreased to $5 \%$ with a nominal value of $10 \mathrm{~dB}$. The maximum rate of gain was $81 \%$ and of loss was $0 \%$.

\section{Acknowledgements}

Not applicable.

\section{Funding}

No funding was received.

\section{Availability of data and materials}

All data generated or analyzed during this study are included in this published article.

\section{Authors' contributions}

HM and MR contributed equally to this work and should, therefore, both be considered first authors of this article. HM and MR were responsible for the original idea, conception, patient selection and care, operations, data collection and editing structure. AIM, AB and GC assisted with patient care and follow-up, gathered the medical information and provided a final view of the article. MAS was responsible for the data analysis and graphical representation of the results and provided a final view of the article. All authors read and approved the final manuscript for publication.

\section{Ethics approval and consent to participate}

For this study, agreement was obtained from the Research Ethics Committee of the Faculty of Medicine, Titu Maiorescu University (resolution 1/25.05.2021). All patients provided informed consent and approved the publication of data.

\section{Patient consent for publication}

Not applicable.

\section{Authors' information}

Horia Mocanu: ORCID: 0000-0002-9708-8285; Adela-Ioana Mocanu: ORCID: 0000-0003-0725-2131; Alexandru Bonciu: ORCID: 0000-0002-5251-4594; Gabriella Coadă: ORCID: 0000-0003-4104-8716; Mihai-Adrian Schipor: ORCID: 0000-0002-2677-9353; Marian Rădulescu: ORCID: 0000-0002-4029-7721. 


\section{Competing interests}

The authors declare that they have no competing interests.

\section{References}

1. Millstein S: The history of mastoid surgery. Am J Otol 1: 174-178, 1980.

2. Alecu I, Mocanu H and Călin IE: Intellectual mobility in higher education system. Rom J Mil Med 120: 16-21, 2017.

3. Çetinkaya EA, Çukurova I, Olgun L and Kabakçi R: Long-term outcomes of functional surgery for attic cholesteatoma. ENT Updates 6: 29-33, 2016.

4. Bento RF and Fonseca AC: A brief history of mastoidectomy. Int Arch Otorhinolaryngol 17: 168-178, 2013.

5. Mukherjee P, Sauders N, Liu R and Fagan P: Long-term outcome of modified radical mastoidectomy. J Laryngol Otol 118: 612-616, 2004.

6. Neudert M, Bornitz M, Mocanu H, Lasurashvili N, Beleites T, Offergeld $\mathrm{C}$ and Zahnert T: Feasibility study of a mechanical real-time feedback system for optimizing the sound transfer in the reconstructed middle ear. Otol Neurotol 39: e907-e920, 2018.

7. Mocanu H, Bornitz M, Lasurashvili N and Zahnert T: Evaluation of Vibrant ${ }^{\circledR}$ Soundbridge ${ }^{\mathrm{TM}}$ positioning and results with laser doppler vibrometry and the finite element model. Exp Ther Med 21: 262, 2021.

8. Mocanu $\mathrm{H}$ and Oncioiu I: The influence of clinical and environmental risk factors in the etiology of congenital sensorineura hearing loss in the Romanian population. Iran J Public Health 48: 2301-2303, 2019

9. Mocanu H: The role of perinatal hearing screening in the normal development of the infant's language. In: Debating Globalization. Identity, Nation and Dialogue. 4th edition. Boldea I and Sigmirean C (eds). Arhipeleag XXI Press, Tirgu Mures, pp562-569, 2017.

10. Mocanu H: The economic impact of early diagnosis of congenital hearing loss. In: Debating Globalization. Identity, Nation and Dialogue. 4th edition. Boldea I and Sigmirean C (eds). Arhipeleag XXI Press, Tirgu Mures, pp556-561, 2017.

11. Cook JA, Krishnan S and Fagan PA: Hearing results following modified radical versus canal-up mastoidectomy. Ann Otol Rhinol Laryngol 105: 379-383, 1996.

12. Fagan PA: Modified radical mastoid surgery for chronic ear disease. Ann Acad Med Singap 20: 665-673, 1991.

13. Perez de Tagle JR, Fenton JE and Fagan PA: Mastoid surgery in the only hearing ear. Laryngoscope 106: 67-70, 1996.

14. Mocanu H, Mocanu AI, Drăgoi AM and Rădulescu M: Long-term histological results of ossicular chain reconstruction using bioceramic implants. Exp Ther Med 21: 260, 2021.

15. Galm T, Martin TP and Raut V: Open and closed cavity mastoid operations: Comparing early hearing results. Eur Arch Otorhinolaryngol 270: 77-80, 2013.

16. Stankovic MD: Audiological results of surgery for cholesteatoma; Short- and long-term follow-up of influential factors. Otol Neurotol 29: 933-940, 2008.
17. Lucidi D, De Corso E, Paludetti G and Sergi B: Quality of life and functional results in canal wall down vs canal wall up mastoidectomy. Acta Otorhinolaryngol Ital 39: 53-60, 2019.

18. Kos MI, Castrillon R, Montandon P and Guyot JP: Anatomic and functional long-term results of canal wall-down mastoidectomy. Ann Otol Rhinll Laryngol 113: 872-876, 2004.

19. Veldman JE and Braunius WW: More than 10 years of revision-cleaning and revision-reconstructive ear surgery in chronic otitis media; good long-term results. Ned Tijdschr Geneeskd 141: 1563-1567, 1997 (In Dutch).

20. Tran Ba Huy P, Chaar I, Fouda A, Almorad M, Brette MD and Freyss G: Anatomical and functional evaluation, after 3 and 5 years, of 94 cases of chronic cholesteatomatous otitis media. Clinical and therapeutic implications. Ann Otolaryngol Chir Cervicofac 105: 29-38, 1988 (In French).

21. Brown JS: A ten-year statistical follow-up of 1142 consecutive cases of cholesteatoma: The closed vs the open technique. Laryngoscope 92: 390-396, 1982.

22. Harvey SA and Fox MC: Relevant issues in revision canal wall-down mastoidectomy. Otolaryngol Head Neck Surg 121: 18-22, 1999.

23. Weiss MH, Parisier SC, Han JC and Edelstein DR: Surgery for recurrent and residual cholesteatoma. Laryngoscope 102: 145-151, 1992.

24. Austin DF: Staging in cholesteatoma surgery. J Laryngol Otol 103: 143-148, 1989.

25. Nyrop $M$ and Bonding P: Extensive cholesteatoma: Long-term results of three surgical techniques. J Laryngol Otol 111: 521-526, 1997.

26. Portmann M, Crovetto MA, Valles J and Aguayo F: Anatomical and functional results of the 'small tympanic cavity' in total petromastoid excision for cholesteatoma. Rev Laryngol Otol Rhinol (Bord) 108: 161-164, 1987 (In French).

27. Parisier SC, Hanson MB, Han JC, Cohen AJ and Selkin BA: Pediatric cholesteatoma: An individualized, single-stage approach. Otolaryngol Head Neck Surg 115: 107-114, 1996.

28. Pareschi R, Lepera D and Nucci R: Canal wall down approach for tympano-mastoid cholesteatoma: Long-term results and prognostic factors. Acta Otorhinolaryngol Ital 39: 122-129, 2019.

29. Vartiainen E: Ten-year results of canal wall down mastoidectomy for acquired cholesteatoma. Auris Nasus Larynx 27: 227-229, 2000.

30. Aslan Felek S, Islam A, Celik H, Demirci M, Samim E and Kose SK: The functional and anatomical results of the canal wall down tympanoplasty in extensive cholesteatoma. Acta Otolaryngol 129: 1388-1394, 2009.

31. Göçmen H, Kiliç R, Ozdek A, Kizilkaya Z, Safak MA and Samim E: Surgical treatment of cholesteatoma in children. Int J Pediatr Otorhinolaryngol 67: 867-872, 2003.

32. Kim MB, Choi J, Lee JK, Park JY, Chu H, Cho YS, Hong SH and Chung WH: Hearing outcomes according to the types of mastoidectomy: A comparison between canal wall up and canal wall down mastoidectomy. Clin Exp Otorhinolaryngol 3: 203-206, 2010.

(i) $\odot$ This work is licensed under a Creative Commons Attribution-NonCommercial-NoDerivatives 4.0 International (CC BY-NC-ND 4.0) License. 